Smith, was summoned, and everything appeared to be going on well up to half-past ten o'clock, when severe convulsions occurred. His attention was immodiately directed towards effecting delivery, and by means of the vectis, the birth of a living boy was easily and speedily effected during the second paroxysm. The placenta was separated readily. Twenty ounces of blood were then withdrawn promptly from the right arm, and a slight opiate administered. As, however, the convulsions recurred with increasing violence, howerer, the o'clock in the morning Mr. Smith requested that I might be sent for. She was then, during the intervals of the fits, talking constantly and moving convulsively, with a screwing-like motion, her hands and arms. Her counteance was florid and turgid, the pupils somewhat dilated, and the legs were odematous. We learned that, during the preceding six weeks, she had been very reluctant to take any active exercise, and had complained of occasional pains darting up to her head; that her ankles had been swollen; that she had been teased with an irritable state of the bowels, and that she had eaten heartily even up to the time that her labour commenced. My opinion that the convulsions in this case were connected with renal disease was grounded not only upon the associated symptoms, but also upon the previous history of our patient; as fourtecn Jears ago she had suffered from an attack of scarlatina, followed shortly afterwards by severe epileptic convulsions, which lasted three days, from the effects of which she recovered slowly. Her natural florid complexion, however, returned gradually, and, with the exception of excessive irritability of temper and indisposition to exertion, she was considered to have been in ordinary health up to the time of her present seizure - not having presented the usual cachectic appearance of a person labouring under structural disease of the kidneys. Any doubt was, howerer, dispelled by an examination of the urine. Mr. Smith, by means of a catheter, obtained six ounces of urine, having a greenish whey-like appearance, coagulable so strongly by heat as to become semi-solid, like blanc mange. A large sinapism was applied to the loins, and some croton oil placed upon the tongue. As the paroxysms returned with increased scrcrity, accompanied by profound coma, loud stertorous breathing, turgid countenance, and increased fullness of pulse, bleeding to sixteen ounces was again had recourse to: this afforded immediate relief to the heary stertor. The state of coma was, however, never rallied from. Another dose of croton oil was placed upon the tongue, and the calves of the legs were vesicated with liquor of ammonia. She gradually sank eighteen hours after the first attack of convulsions.

The blood withdrawn did not appear to be sensibly deficient in red corpuscles. The clot was large, buffed, and abounded in fibrin. The serum was deficient in specific gravity, being only 1019. By a careful analysis I was enabled to detect the presence of urea. The urine withdrawn by catheterism was acid, and of specific gravity 1020 . On cooling, it became opaque, of a grey colour, and pultaceous, like thin oatmeal gruel. It deposited a sediment composed of small organic corpuscles, and an abundance of tubular casts filled with cells and granules. As before noticed, it coagulated strongly both by heat and nitric acid.

REMARKs. In this case, the patient experienced, fourteen years previously, an attack of scarlatina, followed by a severe and prolonged epileptic seizure; then, during an interval of fourteen years, freedom from any decided morbid manifestation, unaccompanied by the usual anæmic condition, and, lastly, rapidly fatal convulsions, associated with an intensely congested state of the kidneys, developed by the puerperal state.

Had her medical attendants been apprised of her condition a few weeks prior to her accouchement, a happier termination, I think, might have been reasonably expected.

Burgh-10-Karsh, Lincolnshire, April s0th, 1855.

\section{CASE OF ACUTE DIABETES MELLITUS SUCCESSFULLY TREATED.}

\section{By T. OGIER WARD, M.D.}

THE following case was mentioned recently at the London Medical Society, as exhibiting the beneficial effects of following a plan of diet and regimen very similar to that recommended by Dr. Headland, in a paper then read to the Society.

The patient, a gentleman aged 53, was a remarkably fine man, the youngest of twenty brothers and sisters, most of whom were equally well grown as himself, but who all died prematurely. He was subject to sore throat, and for tho last nine years to vomiting after his meals, particularly after dinner, and to occasional pains in the right side, which, however, he studiously concealed from me. He lived well, though not a great eater; and his habits were regular; but for the last year or two he had almost given up wine or spirits, drinking $t$ wo or three pints a day, but not often to excess, of Welsh ale, of which he was rery fond. He had for several years suffered from chronic ophthalmia, which had destroyed the sight of one cye, and materially affected that of the other. He was also very corpulent; and, though for the last year he had begun to lose his flesh and strength, still he was not prevented from walking daily one way between Kensington and London, and sometimes he walked to the City and back.

He first consulted me December 27 th, 1853, on account of the vomiting after meals. He then presented the following symptoms in addition: $\Lambda$ gencral feverish condition, indicated by a rapid pulse, hot and dry skin, great thirst, furred tongue, loss of appetite, and high coloured, but abundant urine, about two pints daily, depositing a copious sediment of purpurates and lithates. The bowels were regular, and the motions of a healthy colour. Thinking that I had to treat a feverish state connected with, but dependent upon, an irritable stomach, I prescribed a light diet and abstinence from all stimulants, and a mixture of potassio-tartrate of soda and nitric æether, which was continued for three days. The fever having then abated, and the pulse becoming slower, though still above the usual rate, I turned my attention to the irritation of the stomach, and ordered a mixture of bismuth and magnesia, which I have generally used with success in such cases. The effect of this treatment on the stomach was excellent; the romiting ceased; but the urine, in spite of the magnesia, was still high coloured, and loaded with lithates as before, though it was abundant in proportion to the quantity of fluid drunk. Having taken a specimen for examination, under the idea that from its dark colour the urea would be in excess, I was surprised to find that there was but little more than the proper quantity; and seeing that its specific gravity was 1044, I tested it for sugar, of which it gave abundant evidence by every test that was used. Although the vomiting had ceased, the tongue was still furred; and fearing that, if I left off the bismuth, the symptoms might return, I added some liquor opii sedativus to the prescription, and enjoined a strict attention to the following diet and regimen. For breakfast, tea or coffee, without sugar, but with milk, an egg, and a small quantity of stale crust toasted, or a plain biscuit; for lunch, a chop or oysters, with a small bit of crust, and water to drink; for dinner, meat, with greens or a little turnip and crusts or biscuit, and a small quantity of sherry or brandy and water; and for tea the same as breakfast, without the egg; but this meal he seldom partook of, rarely taking any foud after dinner. As I could not prevent his going into the City daily, the main point in his regimen was to prevent him from taking cold, and to endeavour to keep up perspiration, or at least a free state of the skin, by plenty of clothing by day and night, and carefully aroiding wet feet. In a fow days after the addition of the opium, his stools were clayey, and his bowels rather confined; but this condition was easily remedied by compound rhubarb pill, of which, however, he only took a dozen during his illness. 
I now kept a daily register of the quantity and specific Berity of the urine. On Jannary 20 th; that is, in a little more than a month, the quantity was a pint and a half, of specific graivity 1024. The same treatment was continued to February loth; when, finding that the quantity of urine was stationary at a pint and half, while the specific gravity raried from 1015 to 1023 , and that Mr. L. began to tire of his medicine, I prescribed some phosphate of ammonia, in doses of five grains thrice a day. This, however, was so disagreeable, that on the 13th I ordered the following medicine, as the stomach was rather irritable, and the urine atill thick.

Bo Sodæ hyposulphitis,

Sodæ carbonatis, äa $\bar{z} \mathrm{ss}$

Acidi hydrocyanici dil. (Scheelii) $m \times j$, Aquæ 3j. M.

Fiat haustus ter die sumendus.

This prescription was but little more agreeable than the former; and on the 15 th I returned to the bismuth. The stomach now recovered its tone; Mr. L.'s flesh and strength were returning; and on the 19 th I took my leave, all traces of sugar having disappeared from the urine; its specific gravity was normal, though, as it still continued to contain more than its usual quantity of lithates, I strongly urged him to continue the same diet and regimen, which he promised, and, I believe, continued to observe for some months longer.

In the middle of April I saw him again for the purpose of giving him a certificate respecting the state of his health, in order to prevent his being put under arrest ; and although at that time I could detect no evident disease besides the ophthalmia, which was getting worse, I did not hesitate to declare that, after so recent a recovery from diabetes, the effect of an imprisonment could not fail to be most injurious, if not fatal. Upon this certificate the judgment was allowed to stand over; and I strongly advised him to consult some eminent oculist respecting the condition of his eyes. He did so in July last, and while under treatment he had a sudden attack of jaundice, with pain in the right side; and as the gentleman he consulted did not believe that he had suffered from diabetes, he prescribed mercury, which soon produced a violent salivation, but without any beneficial effect, and he was sent to Margate for change in September, where he was ordered to drink largely of seawater, which he did for a week, when he became disgusted with it. He stayed there about a month, during which time a rash came out on his body, attended with great itching, and bleeding when scratched; and he had ascites and anasarca, though the pain the side was removed. He returned home much worse, having lost his appetite, and the ascites increasing rapidly, so as to prevent his lying down for the last few days of his life. He died November 3rd, still jaundiced and enormously swollen with dropsy.

REмakкs. This case presented several features that appear to me worthy of notice in its origin, progress, and termination. With regard to its origin, the tine when the urine began to be saccharine cannot be fixed with nrecision. but it cannot nrob?hl-- ive referred to an carlier period than that when Mr. L. began to lose his flesh and strength. The urine, however, was not only saccharine, but loaded with lithates, and deeply tinged with purpurine; moreover, it was not much increased in quantity, notwithstanding its saccharine condition; in short, it presented the ordinary appearance it assumes in liver disease, which was doubtless present, although Mr. L. carefully concealed his symptoms by denying that he suffered from pain or any ailment whatever, except the diabetes, which he could not conceal. Indeed his death from liver disease within the year, indi. eated clearly that the condition of the urine depended upon this cause. Assuming, then, that disease of the liver coexisted with the vomiting and the diabetes, the anomaly of a highly saccharine state of the urine, with little increase in its quantity, is explained; for this latter condition, or rather a decrease of the normal quantity, together with an -axcess of the lithates and purpurine, constantly attend disease of the liver. We may, therefore, conclude that the diabetic candition oxiginated in disonder of the stomach induced by indulgence in the use of Weloh ale* (an imperfeetly formented liquor), and was followed by liver diseace, also attributable to the same cause. Next, with regard to the progress of the diabetes, it has been observed by Dr. Prout that the urine does not usually acquire its saccharine character until it ceases to deposit the lateritious sediments, and that a return of these sediments in the urine is a favourable symptom. Dr. Bence Jones also remarks, that when nric acid is found in excess in the urine, it is probable that the diabetes may be temporarily, if not permanently, removed. In the present case, the lateritious deposits not only co-existed with the diabetes, but they continued in great abundance after the urine had lost its saccharine condition; doubtless because, al though the gastric affection on which the diabetes depended was removed, the liver disease was unchecked, and was advancing to its fatal termination. It has also been stated by Dr. Prout that persons affected with diabetes are very liable to be carried off by some intercurrent acute disease-a remark that seems to have been verified in this instance by the sudden attack of pain in the liver and jaundice (probably the effect of the hepatitis passing from a subacute to an acute form), which eventually caused Mr. L.'s death in a few months: and it is much to be regretted that neither the surgeon nor the physician who were consulted gave any credence to the statement of his friends that he had had diabetes, otherwise they would scarcely have subjected him to a course of mercury sufficient to cause profuse salivation, but would have used other means to subdue the lirer disease. The cessation of the diabetes at the same time with that of the irritability of the stomach is an interesting fact in the pathology of this obscure disorder, and connects the two affections together as cause and effect. Up to this attack of romiting, Mr. L. had never had any illness; and the discovery of the presence of diabetes was accidental.

Lastly, with respect to the termination of this case: if so decided an instance of diabetes as is indicated by urine of specific gravity of 1044 may exist, and yet be overlooked, and may be cured, at least apparently, in less than two months from its discovery,-may we not draw a rather more favourable prognosis in the earlier stages of the complaint? and is this not a hint to examine the urinc with care, in order to detect the earliest appearance of the saccharine diathesis? Sugar has been detected in the urine in nervous diseases, epilepsy, pertussis, gout, dyspepsia, boils and carbuncles, Bright's disease, tuberculosis, abscesses, diseascs of the respiratory system, cholera, and old age; and it has been observed occasionally to bc intermittent, as indeed might have been the case in this instance; but, in most of these cases, it has not bcen stated with accuracy whether the urine was abnormal in quantity; what was its specific gravity; nor for how long the saccharine condition continued. One conclusion, however, may be drawn from this list of diseases, viz., that the change in the urine was merely symptomatic, and most probably originated in the stomach, which, more than any other organ, has its functious unswned by sympathy with affections in other parto of the system.

Considered, then, from this point of view, diabetes seems to present a more favourable tield for remefial efforts than it has hitherto been deemed capable of affording; and we may hope that, since other cachectic conditions, as anæmia, scurvy, purpura, dropsy, tuberculosis, and albuminuria, in their early stages, admit of an easy and radical cure, so diabetes also, when detected, and properly treated in its outset, may cease to be one of the opprobria medicorum. Indeed, it is evident that cases of symptomatic diabetes must have hitherto been generally cured without any special treatment, simply because the discovery of the frequent existence of the disease in this form is quite recent ; for, if such cases had not mostly been cured by general treatment, they would have continued to increase in vio

* Welsh ale is usually gweet; and, according to Dr. W. Jones, ale contain from 12 to $120 \mathrm{grains}$ of gugar in the ounce. Most writers on diabetes mention ale drinking as an exciting cause of the disease. 
lence until they attracted attention, the result of which rould have been, thet idiopathic diabetes would have been found to be a rather common, instead of, as it is, a comparatively rare disease.

Applying these observations to the present case, we see that, by a treatment directed to allay irritability of the stomach, and by a carefully but not rigidly restricted diet, well-marked diabetic condition of the urine, with its ata well-marked diabetic condition of the urine, with its atin a few weeks; and it is probable that, if a different treatment for the liver complaint had been substituted for mercury and drinking largely of sea-water, Mr. I.'s life might have been prolonged, if not preserved.

Kensington, May 8 th, 1855.

\section{ON ASPARAGUS AS A DIURETIC.}

\section{By S. J. JEAFFRESON, M.D.}

I HAVE used a tincture of asparagus as a diuretic for sixteen or seventeen years, with increasing confidence in its usefulness and efficacy. I have thought it worth the notice of our Associstios at this particular period, because the time is now approaching at which any gentleman may easily make the experiment of its use. I use the following formula: Take of dried tops of asparagus, five ounces; proof spirit, two pints. Take of fresh tops of asparagus five pounds. Bruise and press out the juice; evaporate at a low temperature till reduced to one pint, and strain. Lastly, add a pint of rectified spirit. Mr. Baly, chemist, of Warwick, can furnish any person desirous of trying the tincture with a limited supply, and will be happy to make any quantity that may be ordered of him.

The peculiar odour communicated by this substance to the urine, in a remarkably short time, is perhaps as familiar to the laity as the profession. It was this fact that first led me to think that asparagus might constitute a valuable adjunct to our list of diuretics; if not indeed by virtue of any specific diuretic quality it possessed, at least by its power of directing other agents of acknowledged diuretic power to the kidneys.

On referring to such authorities as fell in my way, I found that, whilst some mentioned asparagus as a diuretic in general terms, without any specific reference to its medicinal administration, others omitted entirely to notice this plant, and some others denied its diuretic properties entirel5. It appeared to me evident that any deductions drawn on this subject had been founded entirely on its effects as an article of food, and not upon any direct experiments of its medicinal administration. The fallacy and uselessness of such deductions is sufficiently apparent; upon generalisations to vague, we might have discarded numerous of our best remedies as deleterious, innocuous, or useless.

Suffice it to say that, after some sixteen years' experience, I have found the tincture of asparagus a useful ad. junct to our diuretic remedies. In many cases, I have found it possessing direct diuretic properties when taken alone in water; but, in still more instances, I have found it most useful in promoting the diuretic properties of other drugs, as I conceive, by directing them at once to the kidneys. I have repeatedly in my own practice, as also in consultation, simply added from half a drachm to two drachms of tincture of asparagus to each dose of an unsuccessful diuretic, and found that copious diuresis was the result.

Mr. Baly informs me that the exact loss by weight in drying the plant is eleven parts out of twelve; in other words, that twelve parts by weight of the fresh shoots are only equal to one part of dried. I have not tried the infusion of the dry shoots, but should think them worthy of trial.

The tincture of asparagus presents the advantage of being capable of combination, so far as I know by experience, with every diuretic substance in use, be it from the animal, the vegetable, or the mineral kingdom.

Loarington, Yay 4th, 1855.

\section{PHRISCOPIC RHVLHW.}

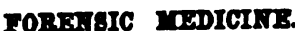

GLEANINGS FROM JOURNALS: WITH REMARKS.

CONYiction of A DENTIST For violatisa A PATIENT WHIE UNDER THE INFLUENCE OF ETHER INHALATION.

There are many instances on record of stupifying drugs having been employed for the purpose of facilitating the perpetration of the crime of rape, and in all legal codes special provision is made for such offenders; and the fact that their provim was unconscious does not in the smallest degree lessen the criminality of the deed. The discovery of the anæsthetic properties of ether and chloroform was, alas! too speedily followed by the application of these arents to criminal purposes. Both in this country and in France cases soon occurrel where, by the use of anresthetic vapours, not only ordinary thieves managed to expedite their robberies, but where professional men were so far left to themselves as to take advantage of the temporary helplessness of their patients and attempt to perpetrate a crime.

The British legislature, alive to the importance of promptly checking the use of anæsthetic agents as an adjuvant to crime, remedied the want in our criminal statutes by iuserting an act which made it a felony to employ chloroform for any such purpose. Since then, no convictions have taken place in this conntry for such offences; in France, however, one or two instances have been recorderl; and very recently in America, (in the town of Philadelphia), a dentist has been convicted of violating a patient while under the influence of ether. The case has excited great attention in America; and since the tria has taken place, the opinion las guined ground that the verdiet of the jury was not justified by the evidence presented. After carefni pertisal of the documents, we have come to the same conclusion, and we consider it our duty to present the case in snch detail as to enable our readers to judge for themselves. Country practitioners are often called unon to use chloroform for the extraction of teeth and other minor operations, where proper assistance is difficult to be had; and professional deutists, to our own knowledge, in such circumstanecs frequently dispense with the presence of a third party. This is wrong : and we trust that the following case mny show the necessity of such an arrangement during the exhibition of the anæsthetic as may save the reputation of practitioners, even though their patients should indulge in hallucinations similar to those which we are about to relate. We avail ourselves of the repurt extracted from the National Police Gazette of Philadelphia, and pub. lished in the Nedical Examiner for December 1854.

A young lady, of nnimpeachable character, who had for some time been engaged to be married, was accompanied by her betrothed to the house of an ancient and higbly respectable dentist, for the nurpose of having one of her teeth plugged. They arrived at his house about ten o'clock on a Friday morning. She entered the house alone, and after " $a$ few niuutes" spent in awaiting the exit of two other ladies, she was ushered into the operatiug room. What followed we give in her own words.

"I went to the oflice; took off my bonnet, and Dr. B. went to the washstand to wash his hands, and he askel me after the family; I took a seat on the operating chair; in a ferr minutes Dr. B.told me one of the men wanted to speak to him, and he gave me a book to read, and left the room; did not say what man; I supposed there were men there; he has a room in which the teeth are made; I believed those to be the men; Dr. B.'s family were out of town at that time; he said so, and the door was opened, and there was no furniture in the front room I don't know how long Dr. B. was absent; when he came back I was sitting in the operating chair; he went to the instrument case, and bergan with my tooth; the tooth was on the left side; he commenced operating on the tooth before he gave me ether; the operation was very painful; he snid he would either pat something in to destroy the nerve, or give me ether, leaving the choice to me; I told him I'd prefer taking ether; I didn't learn what he proposed putting into the tooth; he gave me ether on a small napkin, folded up; I felt very dizzy at first; I was cold and felt very numb; it increased upon me; I did not lose my consciousness of what was doing; I continued to breathe the ether; my eyes were closed; I closed them voluntarily; I did not try to open them for some time after; after he gave me the ether, he did not, as I remember, operate on my tooth; he felt my pulse several times; put his hand on my arm under wy 